\title{
Microenvironmental Variations within the High Tunnel
}

\author{
Hans Christian Wien \\ Department of Horticulture, Cornell University, 156 Plant Science Hall, Ithaca, NY 14853 \\ Additional index words. high tunnel edge effects, cane fruits, winter temperatures, diurnal temperature variation
}

\begin{abstract}
Simple unheated greenhouses covered with clear polyethylene, also known as high tunnels, in which plants are typically grown in the ground have become popular for extending the growing season for high-value horticultural crops. Although they are used principally to produce annual crops such as vegetables and cut flowers, increasing interest has focused on their use for perennial crops such as raspberries, blackberries, and ornamentals. Studies of temperature variation within the tunnel during the growing season have emphasized the rapid rise in air day temperature above ambient during the day and an equally rapid decrease at night. Spatial variation in temperature within the tunnel were much less marked, however, with air temperatures at the edge of a $10-\mathrm{m}$ wide tunnel only $\approx 2{ }^{\circ} \mathrm{C}$ lower than in the center. For perennial crops, tunnel conditions during the off-season are also an important factor. In winter, air temperatures in the tunnel during sunny days rose above freezing even when ambient air temperatures stayed below freezing. Soil temperatures during the day and night fluctuated much less both inside and outside the tunnel and were significantly higher in the tunnel. Studies with nursery plants overwintered in similar structures indicate that spatial variation is again dwarfed by the overall air temperature fluctuation in these structures.
\end{abstract}

Interest in growing vegetables, fruits, and flowers in rudimentary greenhouses covered with a single layer of polyethylene has been increasing in North America in recent years (Carey et al., 2009). These high tunnels offer a low-cost method of extending the growing season at both ends, protecting the growing plants from rain and wind and modifying the interior environment to reduce plant disease pressure (Wien and Pritts, 2008). Use of these structures has been most widespread in Asia and in the countries bordering the Mediterranean, where winter climates are mild enough to permit protected cultivation with minimal inputs (Castilla, 2002; Jiang et al., 2004). Vegetables, strawberries, and cut flowers are most frequently cultivated in high tunnels, and there is increasing interest in producing raspberries and blackberries in them. For these perennial crops, environmental conditions inside during the winter become important as well. In addition, spatial variation in climate within the tunnel takes on increased importance. Although many previous studies have characterized the temperature environment in high tunnels, spatial variation from the edges to middle of the structure or variation at different heights have been little studied (Arellano et al., 2006; Montero et al., 1985; Willits et al., 2006). The objective of the current work is to characterize the high tunnel temperature environment during the growing season and in the winter off-season in the northeastern United States.

\section{MATERIALS AND METHODS}

To characterize the environment in a high tunnel, shielded thermistor temperature probes were installed at $0.5-\mathrm{m}$ height in a pipe-frame gothic greenhouse (http://www. rimolgreenhouses.com/) in Ithaca, NY (long. $42^{\circ} 42^{\prime} \mathrm{N}$, lat. $76^{\circ} 51^{\prime} \mathrm{W}$ ) covered with a single layer of $0.15 \mathrm{~mm}$ clear polyethylene plastic to which infrared (IR) blocking mate-

Received for publication 30 Oct. 2008. Accepted for publication 3 Dec. 2008. rial had been added (Tufflite IV “IR"). High tunnel dimensions were $38 \mathrm{~m}$ length, $9 \mathrm{~m}$ width, and $4.8 \mathrm{~m}$ height, and it was oriented east-west. A shielded sensor was also installed outside the tunnel at similar height and 2.2-m distance from the tunnel side. Soil temperature sensors were inserted $10 \mathrm{~cm}$ below the surface in beds $10 \mathrm{~cm}$ high and $115 \mathrm{~cm}$ wide at the top. Ventilation for the tunnel was provided by sides that could be rolled up to a height of $1.3 \mathrm{~m}$ and manually operated vents with $0.9 \mathrm{~m}$ square dimension placed in the gable ends. During the June measurements, the end doors $(4.9 \mathrm{~m}$ wide and $2.4 \mathrm{~m}$ high) were open, and sensors were placed $13.4 \mathrm{~m}$ from the doors. Temperatures were monitored during early June 2008, when cut flower species were cultivated on five $1-\mathrm{m}$ wide beds covered with black polyethylene plastic in the tunnel and throughout the winter months of 2007-2008 when the high tunnel was empty.

\section{RESULTS AND DISCUSSION}

Spatial variation during the growing season. Early and late in the growing season, when air temperatures outside are typically too low for optimum crop growth, air temperatures rose rapidly in the tunnel when the sun came out as shown for a typical day in Figure 1 . The IR energy produced by the sun greatly exceeded the transmittance of that energy back to the outside. At night, air temperatures rapidly decreased to those outside. Previous work indicates that, depending on the characteristics of the polyethylene covering, the minimum air temperature may drop to lower values than outside the high tunnel. This is the result of the transparency of the film to IR

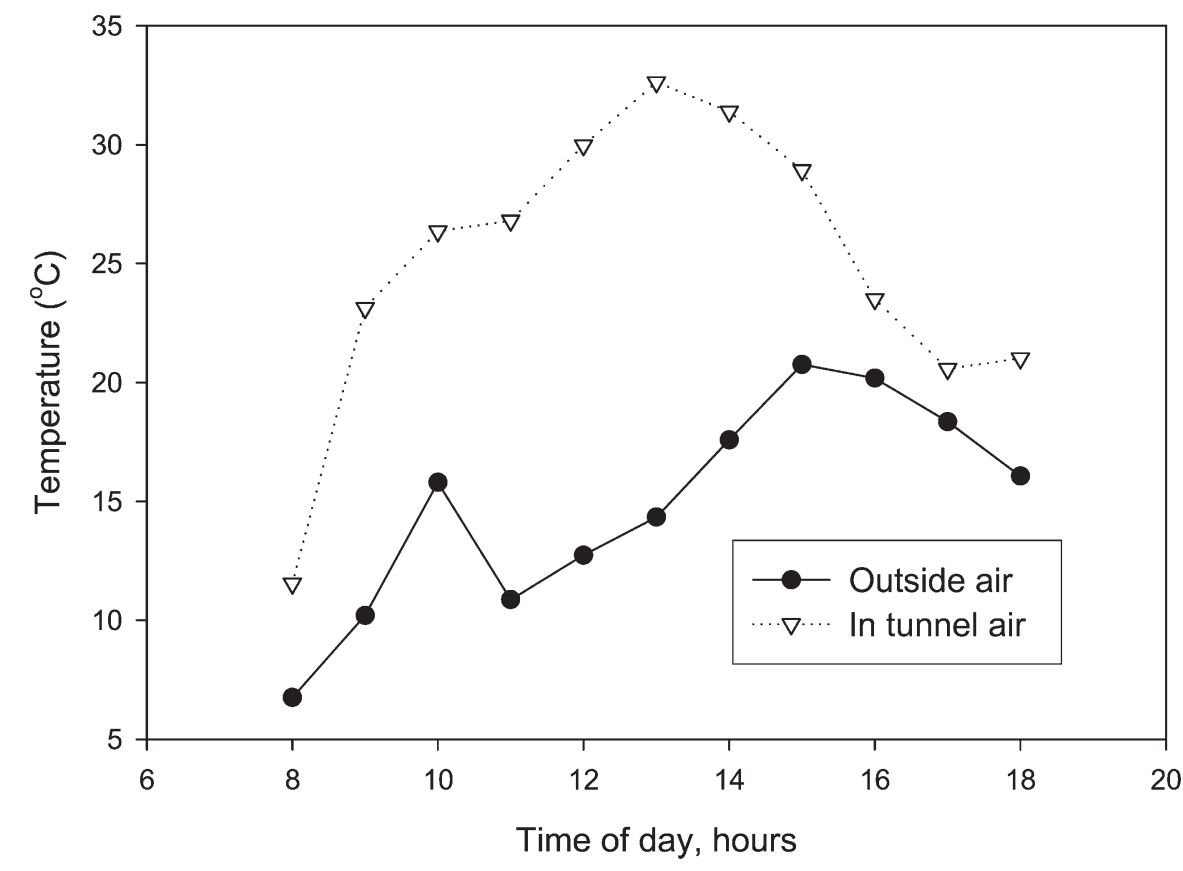

Fig. 1. Air temperature $\left({ }^{\circ} \mathrm{C}\right)$ inside and outside a high tunnel on a sunny day in April 2006 in Ithaca, NY. 


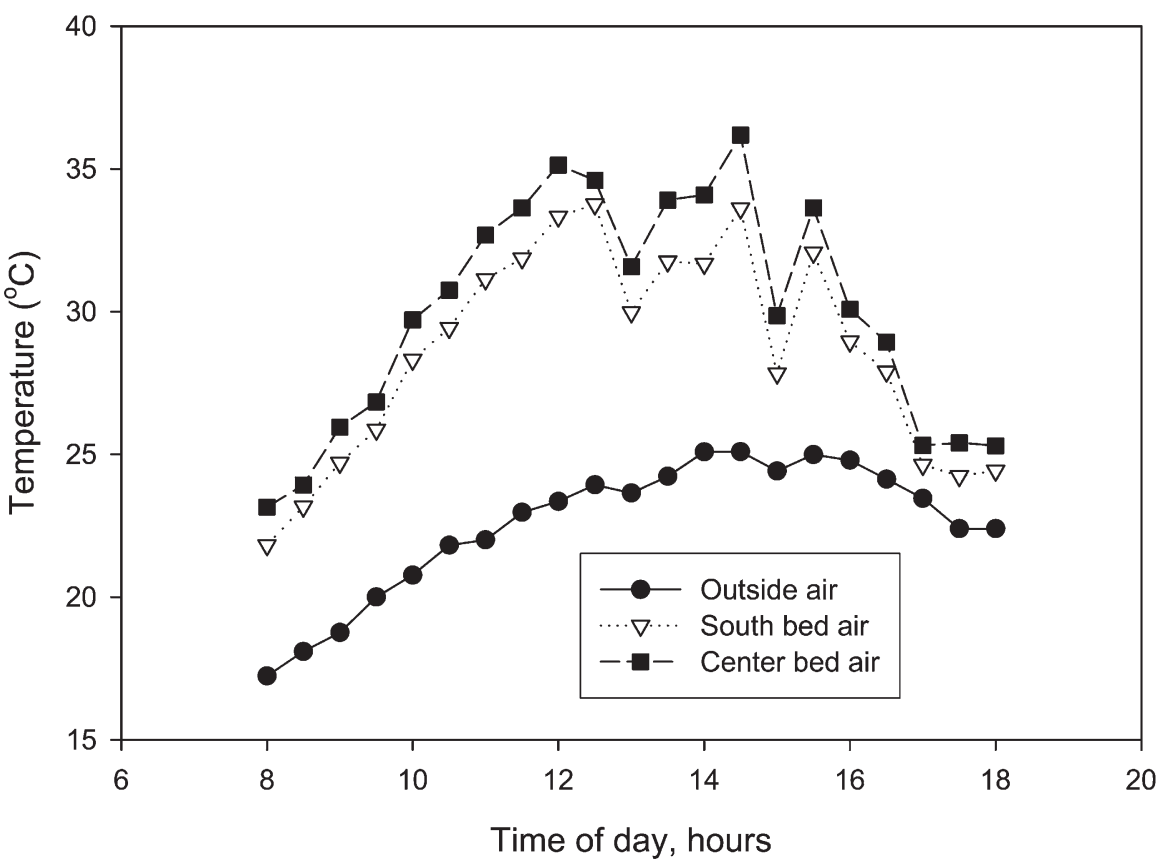

Fig. 2. Air temperature $\left({ }^{\circ} \mathrm{C}\right)$ during the day in two locations in the Ithaca high tunnel and outside averaged for 21 to 24 June 2008. Roll-up sides of the tunnel were open during the period of measurement

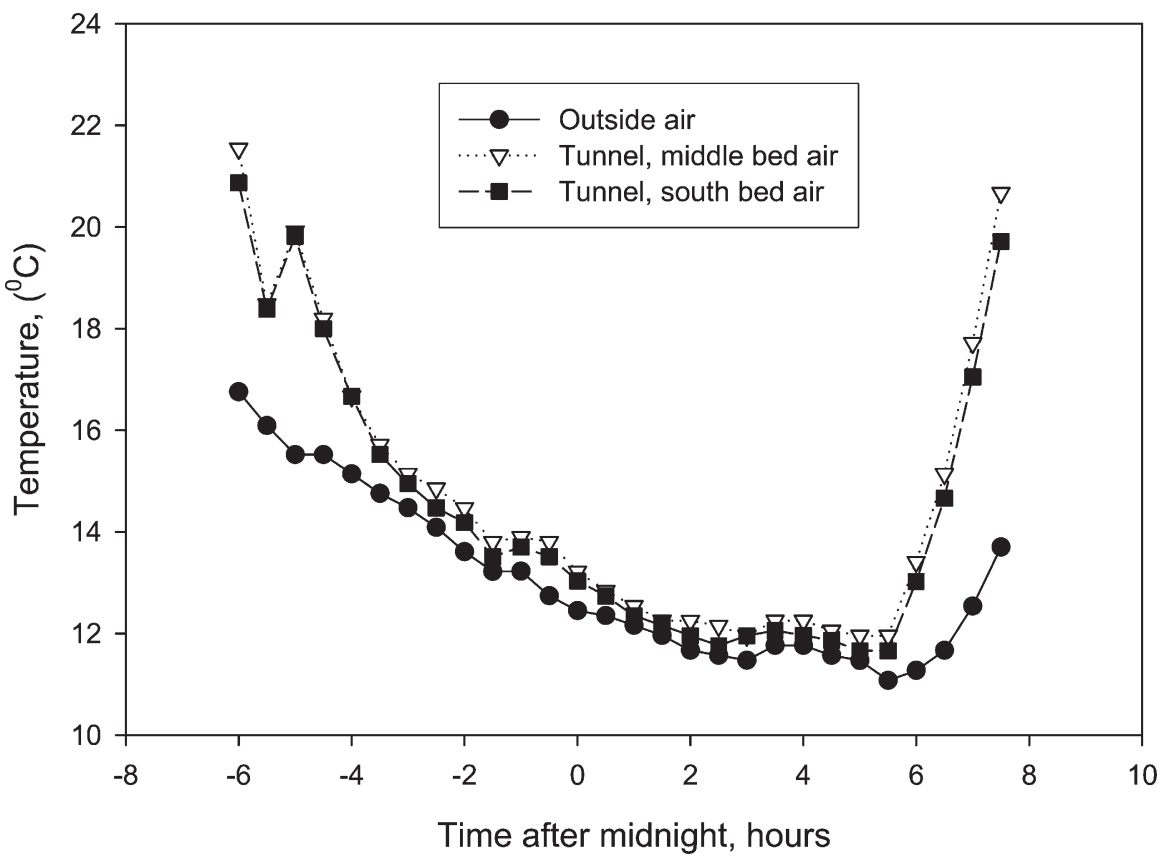

Fig. 3. Air temperature $\left({ }^{\circ} \mathrm{C}\right)$ during the night $(0600 \mathrm{HR}$ to $0800 \mathrm{HR}$ the next morning) in two locations in the Ithaca high tunnel and outside averaged for 18 to 21 June 2008. Roll-up sides of the tunnel and end doors were open during the period of measurement.

radiation and has been documented by several investigators (Baytown et al., 1994; Maia et al., 1990; Montero et al., 1985) and modeled by Albright et al. (1989) and Montero et al. (2005). In that situation, one would expect minimum air temperatures at the edges of high tunnels on cold nights to be higher than in the center of the tunnel, but no one has so far documented this.

During the summer months in the northeastern United States, when outside temper- atures are in the optimum range for crop growth, tunnel vents and end doors are typically left open. Despite this, daytime air temperatures inside exceeded those outside by $10{ }^{\circ} \mathrm{C}$ or more on sunny days (Fig. 2), and beds located near the open side had temperatures 2 to $3{ }^{\circ} \mathrm{C}$ cooler than beds $4.9 \mathrm{~m}$ from that side. At night, the lag in cooling was similar in the beds regardless of location (Fig. 3). Mohammed (1990) and Sase (2006) have documented these temperature patterns and pointed out that they were dictated by ventilation patterns and rates in the structure. As the degree of sides and end door opening is increased, the more similar inside and outside temperatures should become.

Spatial variation during winter. Inside the tunnel, larger fluctuations occurred in air than in soil temperature (Fig. 4). Although outside air temperatures averaged over $4 \mathrm{~d}$ did not rise higher than $-4{ }^{\circ} \mathrm{C}$, they reached $+5{ }^{\circ} \mathrm{C}$ inside the tunnel. In contrast, the soil temperature at $10-\mathrm{cm}$ depth fluctuated little and was only $2{ }^{\circ} \mathrm{C}$ higher inside than outside the high tunnel. By 22:00 HR (Fig. 5), tunnel air temperature was close to that outside and briefly fell below it (Fig. 5). From these patterns, one would expect that plants growing near the edge of the high tunnel would see less temperature variation than in the middle. Although no detailed spatial measurements were made in the winter study, experiments with overwintered nursery pots by Wiest et al. (1976) indicate a similar edge effect as during summer (Table 1). When temperature at the center of the tunnel was $-6{ }^{\circ} \mathrm{C}$, it was 1 to $2{ }^{\circ} \mathrm{C}$ lower at the edge. Air and soil temperatures in the containers showed similar patterns. Other studies with container-grown nursery stock indicated that white polyethylene covers produced less diurnal air temperature variation than clear polyethylene (Rizzo et al., 1981)

The critical variable for winter survival appears to be the temperature of the roots for plants grown in containers. Havis (1976) found that roots were killed before shoots at a given low temperature. The relatively warm soils in high tunnels (Figs. 4 and 5; Kadir et al., 2006) improve chances for winter survival of marginally hardy cane fruits such as primocane-bearing blackberries.

Influence of spatial variation on growth and development. Factors other than temperature also need to be considered in location effects in high tunnels. The improved light climate in the outside rows of greenhouses, for instance, improved yield of trellised tomatoes from six fruits per cluster for plants in the center of the house to eight for the edge plants (Adams et al., 2000). On the other hand, edge effects from increased wind can cause lodging of plants growing near open doors or open sides. Without protective screens, insect pest pressure may be more severe in edge rows of tunnel-grown crops.

To reduce the edge effects with regard to temperature described here, growers select different plant species to grow at the edges and centers of high tunnels. For instance, the most cold-tolerant crops such as garlic, onions, and salad crops are often placed in the outside rows with more tender cucumbers and tomatoes in center beds.

The mitigation of high temperatures that occur especially in the center of naturally ventilated high tunnels has been attempted by the use of screens that reduce irradiance. For instance, Lorenzo et al. (2006) reduced 


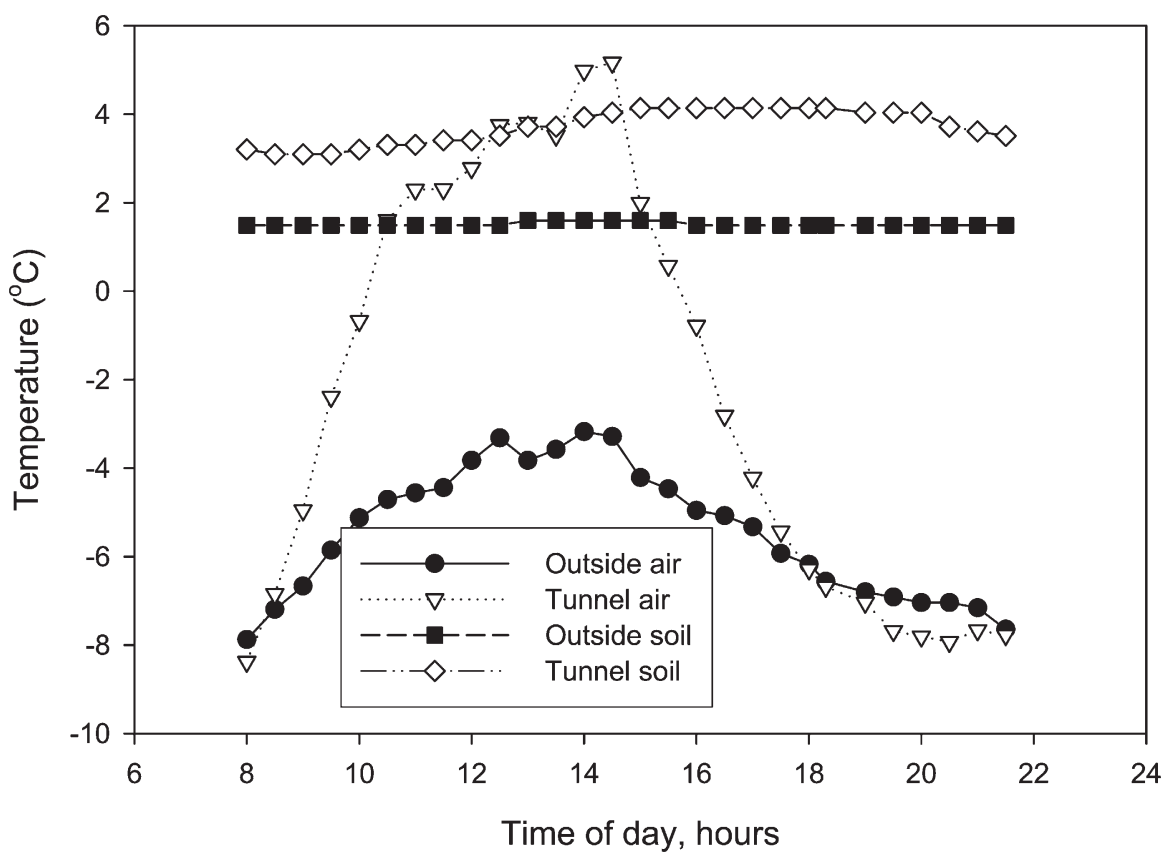

Fig. 4. Temperatures $\left({ }^{\circ} \mathrm{C}\right)$ during the day in the closed Ithaca high tunnel averaged over 18 to $21 \mathrm{Jan} .2008$.

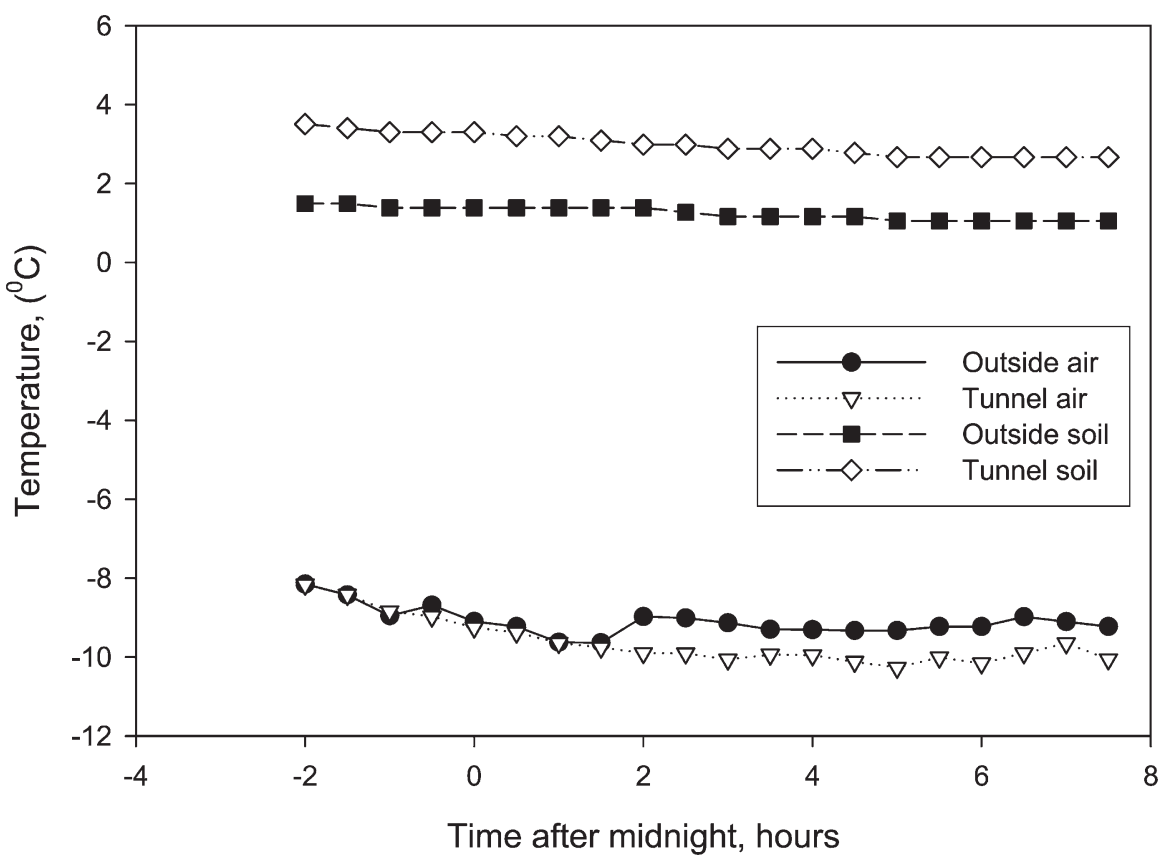

Fig. 5. Temperatures $\left({ }^{\circ} \mathrm{C}\right)$ during the night $(0600 \mathrm{HR}$ to $0730 \mathrm{HR}$ the next morning $)$ in the closed Ithaca high tunnel averaged over 18 to $21 \mathrm{Jan} .2008$.

Table 1. Air and container temperatures $\left({ }^{\circ} \mathrm{C}\right)$ inside the four corners of unheated Quonset huts covered with either clear or white polyethylene in relation to the temperature in the center of the same structures. ${ }^{2}$

\begin{tabular}{lccc}
\hline & \multicolumn{3}{c}{ Temperature at center of house $\left({ }^{\circ} \mathrm{C}\right)$} \\
\cline { 2 - 4 } Tunnel cover & -6 & 0 & +6 \\
\hline Clear cover (air temperature) & $-7.5^{\mathrm{y}}$ & -1.0 & +5.4 \\
White cover (air temperature) & -7.2 & -0.4 & +6.2 \\
Clear cover (soil temperature) & -7.4 & -1.8 & +4.2 \\
White cover (soil temperature) & -8.1 & -0.8 & +4.2 \\
\hline
\end{tabular}

\section{${ }^{\mathrm{z}}$ Data from Wiest et al. (1976).}

'Temperature averages at the four corners of the house, i.e., when air temperature was -6 in the center of the house, temperature in the corners was -7.5 . maximum temperatures by $3{ }^{\circ} \mathrm{C}$ in a plasticcovered greenhouse in Spain using aluminized screens that blocked $50 \%$ of the light. The treatment had no effect on tomato yield, but cucumber yield was increased by $10 \%$. Use of "energy curtains" to increase night temperatures during cool periods has also worked well and would presumably reduce spatial variation in temperature in the tunnel (Both et al., 2007).

Studies indicate that there is moderate spatial variation in temperature in high tunnels both during the temperate growing season and during the winter months. This spatial variation is, however, much smaller than the large temperature fluctuations introduced by tunnel culture. Tunnel edges will tend to be cooler than areas in the middle, but the implications of this location effect will be mitigated by improved light conditions and possible insect pest pressure from surrounding fields.

\section{Literature Cited}

Adams, S.R., V.M. Valdes, P.J.C. Hamer, and B.J. Bailey. 2000. Spatial variation and comparison of yields of tomatoes grown in small experimental compartments with those in large commercial units. Acta Hort. 534:93100 .

Albright, L.D., D. Wolfe, and S. Novak. 1989. Modeling row cover effects on microclimate and yield: II. Thermal model and simulations. J. Amer. Soc. Hort. Sci. 114:569-578.

Arellano, M.A., S. Garcia, A. Sanchez, J. SociaResiz, D. Valera, and M. Urrestarazu. 2006. Greenhouse microclimate and its natural ventilation in two subtypes of an Almeria greenhouse. Acta Hort. 719:147-156.

Baytown, N., K. Abak, H. Tokgoz, and O. Altunas. 1994. Effect of different greenhouse covering materials on inside climate and on the development of tomato plants. Acta Hort. 366:125132.

Both, A.J., E. Reiss, J.F. Sudal, K.E. Holmstrom, C.A. Wyenandt, W.L. Kline, and S.A. Garrison. 2007. Evaluation of a manual energy curtain for tomato production in high tunnels. HortTechnology 17:467-472.

Carey, E.E., L. Jett, W.J. Lamont, Jr., T.T. Nennich, M.D. Orzolek, and K.A. Williams. 2009. Horticultural crop production in high tunnels in the United States-A snapshot. HortTechnology 19:37-43.

Castilla, N. 2002. Current situation and future prospects of protected crops in the Mediterranean region. Acta Hort. 582:135-147.

Havis, J.R. 1976. Root hardiness of woody ornamentals. HortScience 11:385-386.

Jiang, W., D. Qu, D. Mu, and L. Wang. 2004 Protected cultivation of horticultural crops in China. Hort. Rev. (Amer. Soc. Hort. Sci.) 30:115-162.

Kadir, S., E. Carey, and S. Ennahli. 2006. Influence of high tunnel and field conditions on strawberry growth and development. HortScience 41:329-335.

Lorenzo, P., M.L. Garcia, M.C. Sanchez-Guerrero, E. Medrano, I. Caparros, and M. Gimenez. 2006. Influence of mobile shading on yield, crop transpiration and water use efficiency. Acta Hort. 719:471-478.

Maia, M.B., A.A. Monteiro, and J.F. Maneses. 1990. The influence of two different polyethylene 
films on greenhouse minimum temperatures and yield of a tomato crop. Acta Hort. 263:265-274.

Mohammed, B. 1990. Comparaison de la distribution des temperatures sous abrichauffe par la geothermie. Acta Hort. 263:213224.

Montero, J.I., N. Castilla, E. Gutierrez de Rave, and F. Bretons. 1985. Climate under plastic in the Almeria area. Acta Hort. 170:227234.
Montero, J.I., P. Munoz, A. Anton, and N. Iglesias. 2005. Computational fluid dynamic modeling of night-time energy fluxes in unheated greenhouses. Acta Hort. 691:403-409.

Rizzo, C.F., T.A. Fretz, and E.M. Smith. 1981. Evaluation of plastic films used to cover woody ornamental winter storage structures. Scientia Hort. 14:181-190.

Sase, S. 2006. Air movement and climate uniformity in ventilated greenhouses. Acta Hort. 719:313-323.
Wien, H.C. and M.P. Pritts. 2008. Use of high tunnels in the Northeastern USA: Adaptation to cold climates. Acta Hort. (in press).

Wiest, S.C., G.L. Good, and P.L. Steponkus. 1976. Analysis of thermal environments in polyethylene overwintering structures. J. Amer. Soc. Hort. Sci. 101:687-692.

Willits, D.H., S. Li, and C.A. Yunker. 2006. The cooling performance of naturally-ventilated greenhouses in the Southeastern USA. Acta Hort. 719:73-80. 